\title{
DIRECT ADDRESS IN ENGLISH INTERVIEW: VARIATIONS OF MELODIC PATTERNS
}

\author{
Natalya Yu. Sorokoletova \\ Volgograd State University, Volgograd, Russia
}

\begin{abstract}
The paper presents the results of analysis of direct address melodic patterns in radio and TV interviews in English. The address serves to establish, break, and hold the conversation, change the topic, draw attention, express communicative tonality in the English interviews under study. In speech practice the position of address is not strictly regulated, it may be in an absolute, initial, middle and final position in the expression. The position and function of direct address govern the choice of address melodic pattern. Direct address often accompanies other speech acts (greeting, thanking, introducing, farewell, and compliment). The phonetic study based on the material of English interviews allows to describe functional peculiarities of some melodic patterns of address. It is proved that an address at the beginning of the interview (when realized in preposition or postposition) performs a contact-setting function, has different patterns of pitch variation (Level, Low Fall, Mid Fall, Rise-Fall) or may complete the melodic pattern of the previous statement. In the body of the interview, the address may be in an utterance-initial or utterance-final position and serves to resume and hold the conversation, attract listener's attention to the topic. In this part of the interview the address is realized with Low/Mid/High Fall, Fall-Rise, Low Rise, Rise-Fall tones. In the final part of the interview, the address is realized in preposition to other speech acts, serves to break the contact and has different melody patterns: Low/Mid Fall or Fall-Rise. The final address may not form a separate syntagma and have a separate melodic pattern.
\end{abstract}

Key words: direct address, interview, phatic function, melodic pattern, tone.

Citation. Sorokoletova N.Yu. Direct Address in English Interview: Variations of Melodic Patterns. Vestnik Volgogradskogo gosudarstvennogo universiteta. Seriya 2, Yazykoznanie [Science Journal of Volgograd State University. Linguistics], 2018, vol. 17, no. 3, pp. 70-79. (in Russian). DOI: https://doi.org/10.15688/jvolsu2.2018.3.7

\section{ВАРИАТИВНОСТЬ МЕЛОДИЧЕСКИХ ПАТТЕРНОВ ОБРАЩЕНИЯ В АНГЛОЯЗЫЧНОМ ИНТЕРВЬЮ}

\author{
Наталья Юрьевна Сороколетова \\ Волгоградский государственный университет, г. Волгоград, Россия
}

\begin{abstract}
Аннотация. В статье представлены результаты комплексного экспериментально-фонетического анализа мелодических паттернов обращения в радио- и телеинтервью на английском языке. Установлено, что в англоязычных интервью обращение служит для установления, поддержания, восстановления, завершения 位, смены темы, привлечения внимания, выражения коммуникативной тональности. В речевой практике позиция обращения не является строго регламентированной, оно может находиться в абсолютной, начальной, серединной и финальной позициях в высказывании, что влияет на мелодические паттерны его благодарности, представления, прощания, комплимента). Проведенное фонетическое исследование позволило выявить некоторые закономерности функционирования мелодических средств в формулах обращения. Установлено, что обращение в начале интервью представлено в препозиции или постпозиции, выполняет контактоустанавливающую функцию и может быть произнесено ровным, низким или средним нисходящим, восходяще-нисходящим тоном или продолжать мелодический рисунок предыдущего высказывания. В ос-
\end{abstract}


новной части интервью обращение оформляется низким, средним или высоким нисходящим, нисходящевосходящим, низким восходящим, восходяще-нисходящим тоном или продолжает мелодический паттерн предыдущей фразы. В этой части интервью обращение служит для возобновления контакта, привлечения внимания слушающего к теме дискуссии, поддержания контакта, размыкания контакта и может употребляться в препозиции или интерпозиции. В финальной части интервью обращение представлено в препозиции к другим речевым актам, используется для размыкания контакта и оформляется низким нисходящим или нисходяще-восходящим тоном. Финальное обращение может не образовывать отдельную синтагму и не иметь самостоятельного мелодического рисунка.

Ключевые слова: обращение, интервью, фатическая функция, мелодический рисунок, тон.

Цитирование. Сороколетова Н. Ю. Вариативность мелодических паттернов обращения в англоязычном интервью // Вестник Волгоградского государственного университета. Серия 2, Языкознание. - 2018. - Т. 17, № 3. - C. 70-79. - DOI: https://doi.org/10.15688/jvolsu2.2018.3.7

\section{Введение}

В связи с возросшим интересом к особенностям речевого поведения человека в ситуациях межличностного контакта в современной теории коммуникации появляются работы, ориентированные на обобщение данных о функциональной значимости различных форм речи, которые образуют общие и национально-специфичные слои коммуникации. В данном исследовании объектом анализа избрано обращение как разновидность коммуникативной единицы, используемой для называния лица или лиц с целью привлечения внимания, выражения просьбы, приветствия, приказа, сочувствия, соболезнования и т. д.

Обращение неоднократно попадало в фокус внимания как отечественных, так и зарубежных ученых, при этом оно рассматривалось в разных аспектах: установлены его синтаксические (А.M. Мухин, G.O. Curme, R.B. Long и др.) и семантические (В.Е. Гольдин, В.И. Карасик и др.) функции; выявлена специфика реализации обращения различными частями речи (А.В. Велтистова, О.Г. Ветрова, О. Jespersen, С.Т. Onions и др.); описаны языковые и коммуникативно-прагматические нормы употребления (Н.И. Адамушко, В.А. Доборович, Т.С. Жукова, В.И. Карасик, G. Leech, S.M. Ervin-Tripp и др.); обращение охарактеризовано с точки зрения прагматики и теории речевых актов (Н.Д. Арутюнова, В.Е. Гольдин, О.Г. Минина, Н.И. Формановская, D. Wunderlich и др.); установлено место обращения в структуре различных типов дискурса (В.В. Звягинцева, Е.Ю. Нестеренко, Т.Е. Янко и др.); проведен сравнительно-сопос- тавительный анализ реализации обращения в разных языках и в вариантах одного языка (В.Г. Дыкова, С. Митали, Е.Ю. Нестеренко, А.Д. Садовая и др.); выявлены интонационные особенности обращения (С.В. Кодзасов, М.В. Панкратова, А.Е. Садовая, Т.Е. Янко, А. Brugos, S. ShattuckHufnagel, L. Varga, N. Veilleux, и др.).

Исследователи подчеркивают, что обращение является одним из главных средств универсального характера, выработанных языком для обслуживания человеческого общения, для установления связи между высказываниями и субъектами общения, для интеграции разных сторон и компонентов ситуации общения в единый коммуникативный акт [Гольдин, 2009 , с. 4]. По своей природе обращение полифункционально. К его основным функциям относятся: номинативная (обозначение в качестве адресата того, к кому обращена речь), социально-регулятивная (этикетная), фатическая (способствует созданию, сохранению и поддержанию связей между людьми), оценочно-характеризующая. Полифункциональность обращения во многом объяснятся тем фактом, что оно редко реализуется вне других речевых актов (например, приказа, приветствия, прощания, просьбы и т. д.). При этом отмечается, что обращение может входить в цепочку речевых актов, создавая эффект смешения иллокутивных сил и функций, подчиняя свою иллокутивную силу иллокутивной силе акта сообщения, акта приказа или просьбы, акта совета, акта запрета, акта извинения и т. п. [Кожухова, 2007, с. 82].

Обращение описывается и как элемент речевого этикета, стереотипная форма речи, регулируемая правилами речевого поведения и служащая для установле- 
ния, поддержания и прерывания контакта собеседников в избранной тональности [Формановская, 1989, с. 75]. Тональность обращения зависит, по мнению Н.И. Формановской, прежде всего, от экстралингвистических факторов (социальных, гендерных, сферы и условий общения и т. д.) и является своеобразным маркером отношений участников коммуникации. Отметим, что тональность в данном контексте можно определить как характеристику речевой практики, особый мелодический паттерн речевого поведения, позволяющий транслировать информацию о статусных и межличностных отношениях коммуникантов в разных типах и сферах общения.

Цель настоящего исследования - выявить зависимость вариативности мелодического паттерна (рисунка) англоязычного обращения от его положения в высказывании и интенциональности выполняемой функции (функций) в жанре радио- и телеинтервью.

\section{Методика}

Комплексное экспериментально-фонетическое исследование специфики мелодического паттерна обращения проводилось в несколько этапов: отбор и предварительный лингвистический анализ экспериментального материала; перцептивный анализ мелодических особенностей англоязычного обращения в инициальной, срединной и финальной позициях; акустический анализ особенностей реализации обращения в указанных позициях; сопоставление полученных результатов и их функциональная интерпретация.

Материалом исследования послужили аудио- и видеозаписи англоязычных интервью, представленных в радио- и телевизионных программах: «The Andrew Marr Talk show» (https://www.bbc.co.uk/programmes/b0080bbs), «HardTalk show» (https://www.bbc.co.uk/ programmes/n13xtmdc), «FreshAir show» (https:// www.npr.org/programs/fresh-air/).

На предварительном этапе отбора и анализа экспериментального материала все выявленные примеры употребления обращений были сгруппированы в зависимости от:

а) расположения обращения в той или иной композиционной части интервью (в на- чале, в основной части, в заключительной части);

б) позиции обращения в высказывании (абсолютная, инициальная (препозиция), медиальная / срединная (интерпозиция) и финальная (постпозиция)).

Сгруппированные примеры подверглись контекстному и функциональному анализу для выявления функциональной специфики исследуемых обращений. Далее проводился комплексный перцептивно-акустический анализ мелодических особенностей каждого типа обращения, который состоял из следующих этапов:

- определение локализации тонального (мелодического) изменения в границах обращения;

- определение направления тона (ровный, нисходящий, восходящий, нисходяще-восходящий, восходяще-нисходящий), его уровневых (низкий, средний, высокий) и диапазональных (узкий, широкий) характеристик.

Акустический анализ корпуса примеров проводился с помощью программы акустического анализа Speech Analyzer (https:// software.sil.org/speech-analyzer/) и имел целью установление тональных особенностей каждого типа обращения.

\section{Результаты исследования}

В структуре интервью формулы обращения являются облигаторным элементом, однако их позиция, форма и мелодическая реализация демонстрируют вариативность.

Большую часть исследуемого материала составили радио- и телеинтервью, в которых интервьюируемый - это известная политическая или общественная личность, а следовательно, как показано Л.А. Артемовой, в них социальный статус референта маркирован дескриптивным указателем на род деятельности, занимаемую должность, образование [Артемова, 2016, с. 38]. Именно публичные обращения, в которых социальный статус человека «устанавливается в значении слов, употребляемых в функции обращения и выражающих соотносительную позицию человека в социальной иерархии» [Карасик, 1992, c. 222], являются наиболее частотными в нашем материале. 
Н.Ю. Сороколетова. Вариативность мелодических паттернов обращения в англоязычном интервью

Рассмотрим функциональные и мелодические особенности обращения в зависимости от их расположения в общей композиции интервью. К облигаторным элементам жанра интервью следует отнести начальное расположение обращения, входящего в структуру речевых актов приветствия и представления. В данной позиции реализуются фатическая и этикетная функции обращения, выражающиеся в способности устанавливать контакт, а также задавать положительную тональность высказывания.

Контактоустанавливающие реплики строятся в соответствии с типовой формулой публичного приветствия или представления и предполагают использование обращения. Обращение является обязательным для ведущего, при этом выбор формы обращения определяется статусным характером участников коммуникации, например:

(1) Prime Minister Sergey Lavrov, welcome toHT

So, Prime Minister, the negotiations to leave the European Union begin.

Комплексный перцептивно-акустический анализ данной формы установления контакта показал, что обращение находится в препозиции и является частью приветствия и представления гостя. Оно может иметь разнообразный мелодический рисунок и оформлять- ся низким нисходящим (31\%), средним нисходящим (27\%), ровным (25\%), восходященисходящим (4 \%) тоном или не иметь самостоятельного мелодического паттерна (13\%).

Нисходящий тон с различным уровнем понижения характерен для обращений, выступающих в контактоустанавливающей функции и находящихся в препозиции к последующему высказыванию. Низкий и средний нисходящий тоны используются, прежде всего, в официальном обращении, они также позволяют подчеркнуть серьезность и важность сказанного впоследствии. В следующем примере обращение Michael оформлено низким нисходящим тоном:

(2) Michael, welcome to the Interview.

В функции установления контакта мелодический рисунок обращения может быть ровным, что свидетельствует о тесной связи обращения с последующим приветствием (рис. 1).

Ровный терминальный тон, как правило, характерен для незаконченных синтагм, тесно связан с последующей синтагмой и используется в том случае, когда говорящий уверен, что он владеет вниманием собеседника. Ровный тон речи настраивает слушателя на продолжение сообщения.

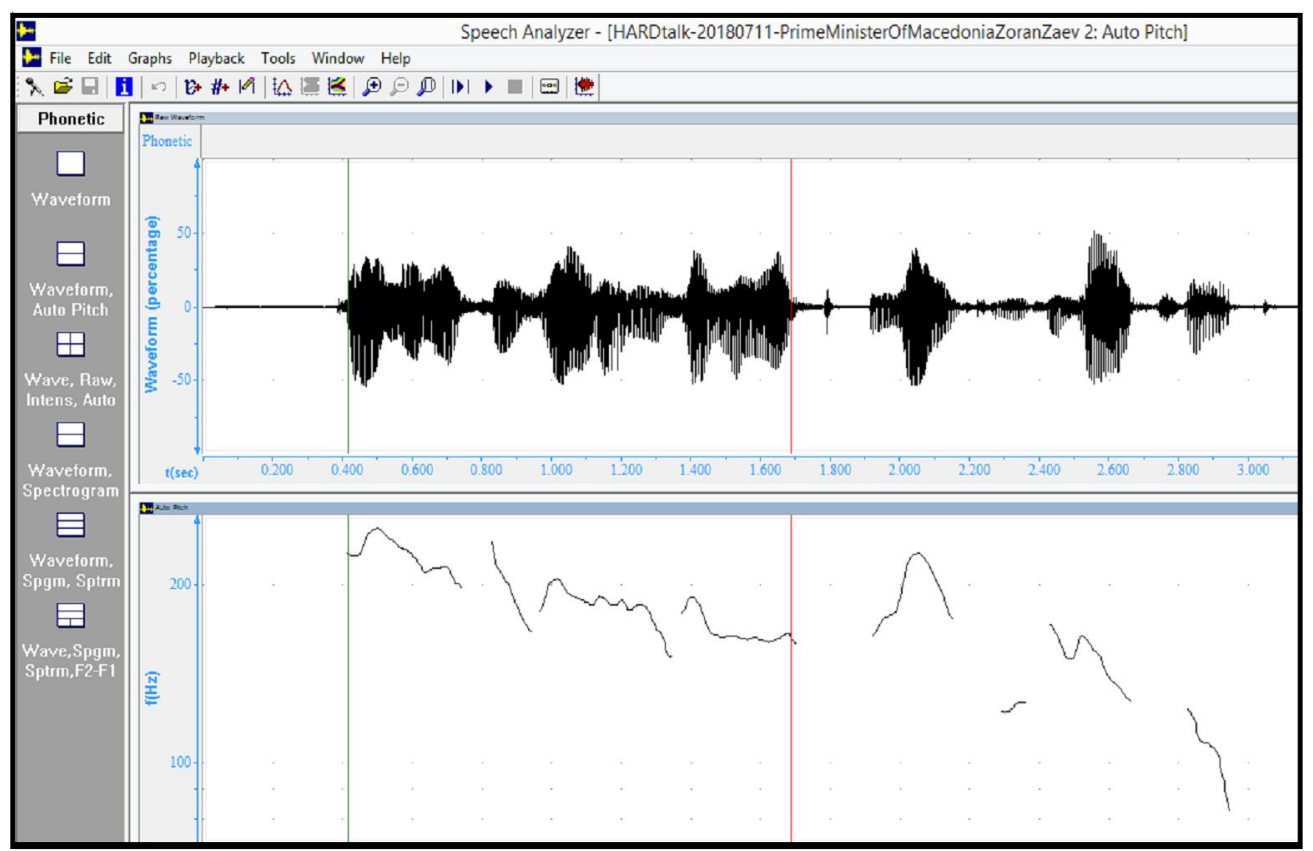

Рис. 1. Интонограмма предложения Prime minister Zoran Zaev, welcome to HardTalk 
В функции установления контакта обращения могут не иметь самостоятельного мелодического выделения, примыкать к предыдущей части предложения (то есть находиться в постпозиции), составляя с ней одну синтагму. Обращение в этой позиции бывает часто подчинено предыдущей интонационной группе, то есть продолжает ее мелодический паттерн. В нижеследующем примере обращение Andrew находится в постпозиции по отношению к приветствию $\mathrm{Hi}$, образуя с ним единый мелодический рисунок (нисходящевосходящий тон) (рис. 2).

В интервью обращение может находиться в абсолютной постпозиции. Так, в следующем примере журналист представляет тему выпуска и своего собеседника, затем повторно использует антропоним Mandy, передавая таким образом слово гостю:

(3) I asked a product packaging designer Mandy Witchell why this is the case. Mandy?

Обращение выполняет в этом примеpe собственно номинативную функцию и оформляется восходяще-нисходящим тоном (см. рис. 3).

Анализ практического материала показал, что в основной части интервью обращения могут быть использованы для возобнов- ления контакта, смены темы, поддержания контакта, активизации и привлечения внимания к определенной теме, переключения ролей. Обращения в этой части интервью могут оформляться нисходяще-восходящим (31\%), нисходящим (низким (17\%), средним $(16 \%)$ или высоким (10\%)), низким восходящим (17 \%), восходяще-нисходящим (5 \%) или продолжать мелодический паттерн предыдущего высказывания (4 \%).

Интервью в рамках радио- и телевизионных программ часто характеризуются продолжительными паузами (например, во время включения рекламных блоков), и возобновление контакта обозначается обращением как средством подтверждения того, что актуализованный ранее контакт с данным партнером поддерживается. Такие случаи обращения отличает нисходящий или восходяще-нисходящий тон (см. рис. 4).

Жанровой спецификой публичных интервью является возможность участия в них нескольких приглашенных гостей. В таком случае обращение находится в препозиции к остальной части высказывания, функционирует самостоятельно (вне других речевых актов) и выступает в номинативной функции, то есть служит для переключения ролей, внимания с одного говорящего на другого. Называя гостя по имени, журналист выделяет адресата

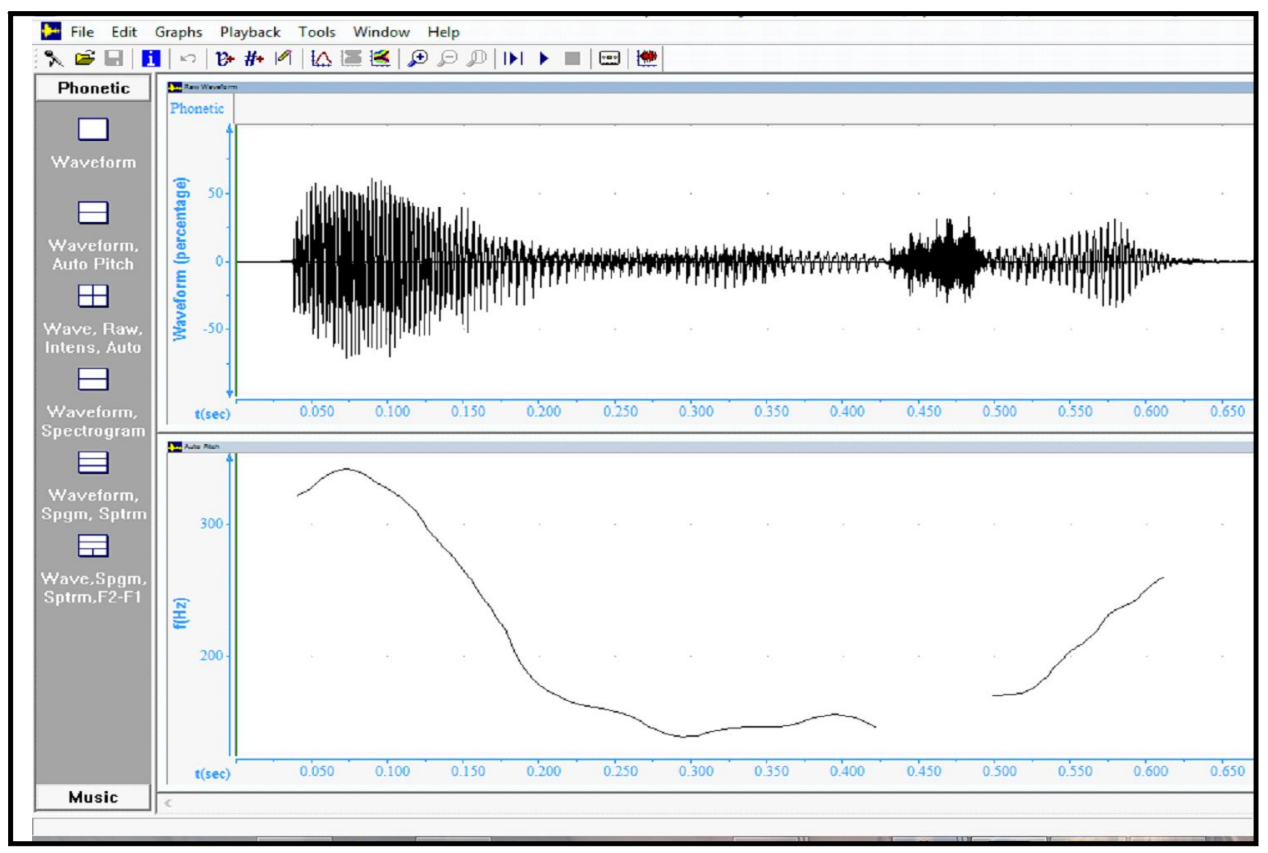

Рис. 2. Интонограмма предложения $H i$, Andrew 
Н.Ю. Сороколетова. Вариативность мелодических паттернов обращения в англоязычном интервью

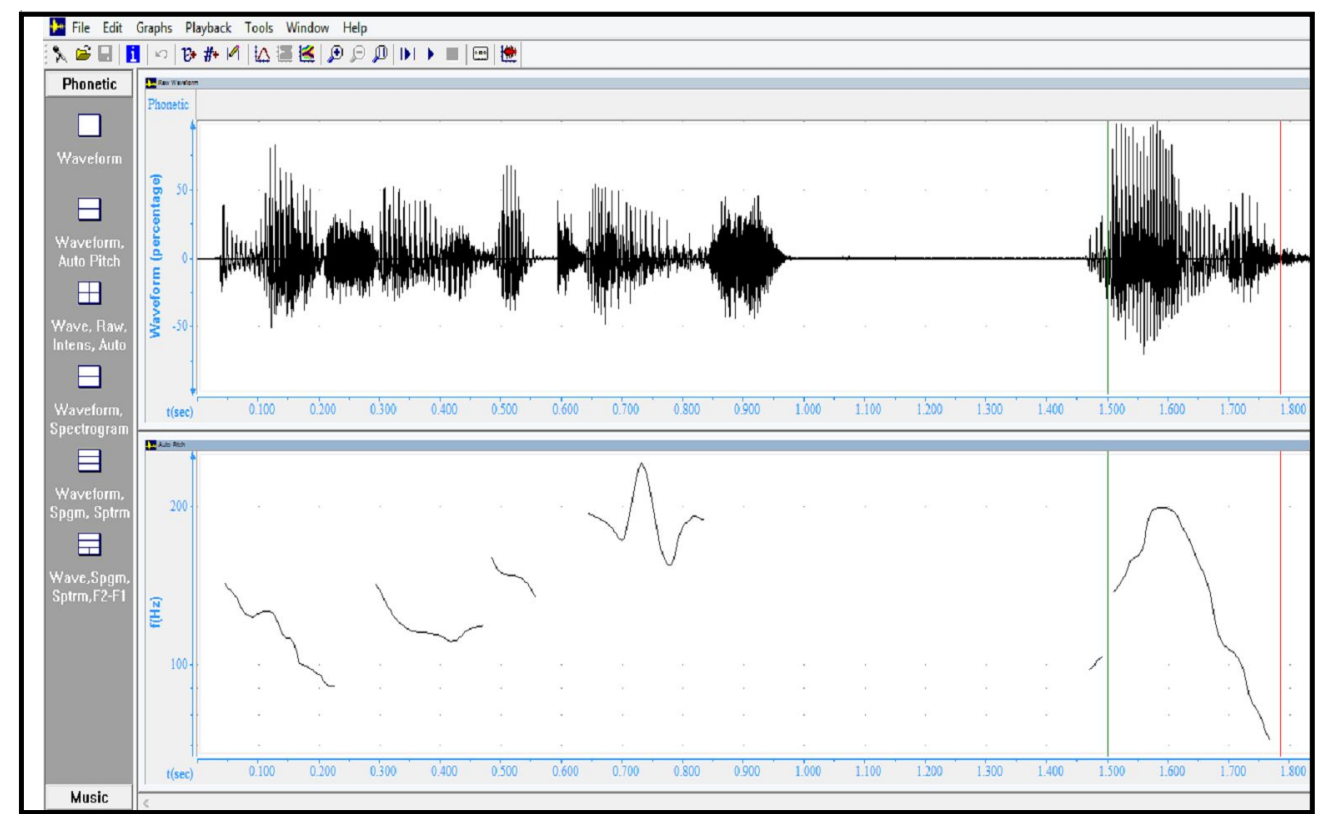

Рис. 3. Интонограмма предложения Mandy

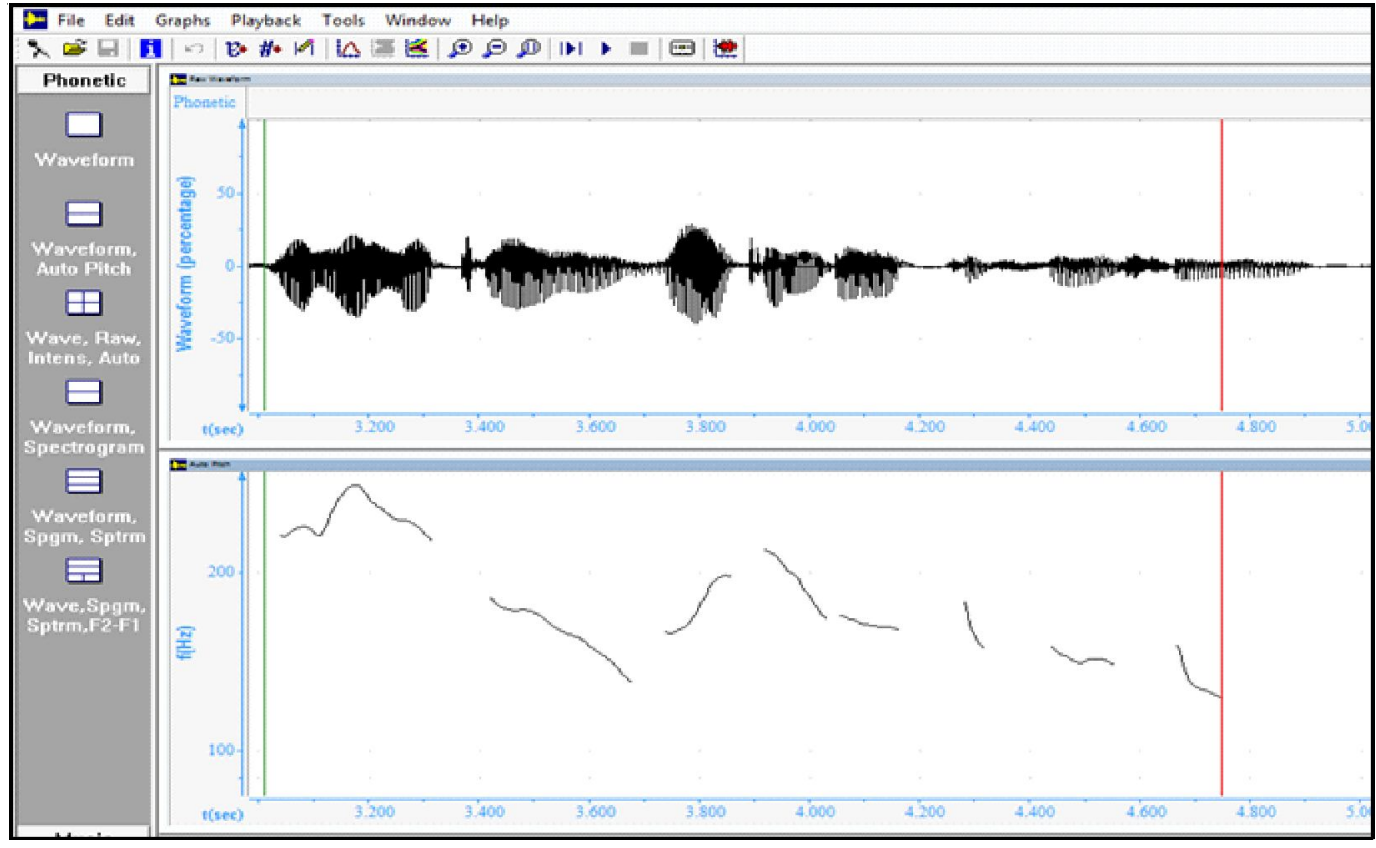

Рис. 4. Интонограмма предложения Stephen McCauley, welcome back to FRESH AIR

речи, а гость идентифицирует себя как получателя информации. В нижеследующем примере журналист берет интервью у британского принца Уильяма и его будущей супруги Кейт Миддлтон (интервью 2010 года) и постоянно обращается к ним:

(4) Tom Bradby: People are obviously very curious about you, so let's start with the obvious. William, where did you propose, when, how. And Kate, what did you say? <.. > Kate, for you. You've had a long time to sort of contemplate this moment.

Начиная предложения с обращения, журналист идентифицирует человека, которому адресует вопрос, привлекает именно его внимание.

В данной позиции и функции обращение оформляется нисходящим тоном (чаще высокого и среднего уровней) или нисходяще-восходящим тоном (см. рис. 5). 


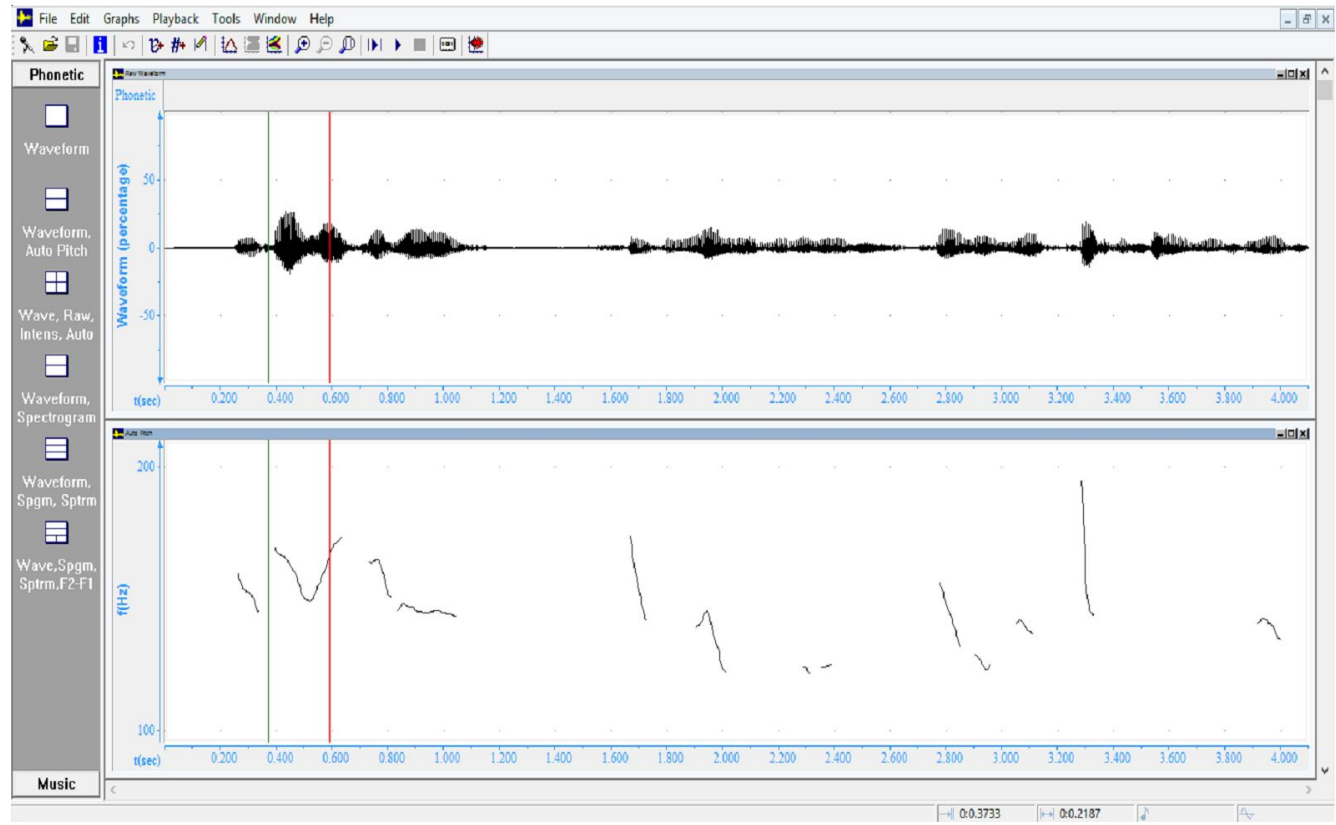

Рис. 5. Интонограмма предложения “Kate, what did you think of William?”

В основной части интервью возможно использование обращения в интерпозиции. Основная функция такого обращения - поддержание контакта и / или привлечение внимания к наиболее значимой информации:

(5) And I really - you know, I finally accepted, Terry, the fact that I am not Tolstoy.

It was the NHS on the side of the bus, Prime Minister, during the referendum.

Проведенное исследование показало, что в английском языке обращение в интерпозиции в большинстве случаев оформляется низким нисходящим или низким восходящим тоном. Подобное мелодическое оформление обычно ассоциируется с грамматической и логической незавершенностью, тесной связью с последующим высказыванием, способствует поддержанию внимания адресата, настраивает на продолжение контакта. В середине предложения обращение также может быть безударно и продолжать общую мелодику фразы.

В современных публичных интервью встречаются случаи смены тональности с позитивной на негативную. Смена тональности может проявляться при переходе коммуникативной роли от одного участника диалога к другому. Данный процесс может осуществляться гладко, естественно, что проявляется в мелодике позитивной тональности, а может перейти в негативную тональность, если один коммуникант не согласен с предыдущей репликой своего собеседника или хочет навязать свои идеи, мнение, эмоции и для этого перебивает говорящего. Такой переход нарушает принципы коммуникативного сотрудничества, вежливости и такта [Янковская, 2012, c. 316].

(6) Sergey Lavrov: What I did say was that the White Helmets are known to work only on the territories controlled by the opposition, including Jabhat an-Nusra, and that White Helmets are known to be ringing the bell one year ago in Khan Shaykhun which was a fake from the beginning to the end and the White Helmets are known to be financed, among other countries, by the United Kingdom...

Question: But Foreign Minister, that doesn't represent an irrefutable proof.

В данном примере журналист перебивает собеседника, используя для передачи несогласия официальное обращение. Размыкание контакта посредством официального обращения, возможно, свидетельствует о желании интервьюера сохранить нейтральную тональность общения. В то же время обращение реализуется высоким нисходящим тоном широкого диапазона, который не свойственен обращению (особенно официальному) при прерывании контакта.

В конце интервью при реализации функции размыкания контакта обращение может 
Н.Ю. Сороколетова. Вариативность мелодических паттернов обращения в англоязычном интервью

быть оформлено средним нисходящим (39 \%), низким нисходящим (31\%), нисходяще-восходящим тоном (13\%) или не иметь отдельного мелодического паттерна (17\%).

Исследование показало, что обращение в конце интервью реализуется в составе речевого акта благодарности (который, как правило, является облигаторным элементом финального этапа интервью) и / или речевого акта прощания, комплимента, пожелания:

(7) Adam Liptak, it is always a pleasure to talk with you. Thank you so much.

Prime Minister, thank you.

Для данной позиции характерно инициальное расположение обращения, которое часто реализуется средним нисходящим, низким нисходящим или нисходяще-восходящим тоном (рис. 6).

Выше отмечалось, что обращение в финальной части интервью реализуется вместе с другими речевыми актами. Исследование показало, что подобное соседство может быть оформлено одинаковым мелодическим контуром. По мнению Т.Н. Янко, это может происходить, если за обоими речевыми актами стоит объемлющая иллокутивная сила (обращение и благодарность в функции завершения контакта) [Янко, 2010, с. 457-458]. На рисунке 7 представлен пример мелодического офор- мления обращения и благодарности в предложении (см. рис. 7).

(8) Prime Minister Lee Hsien Loong, thank you so much for being on HARD Talk.

Для мелодического паттерна обоих речевых актов характерно небольшое повышение в начале и среднее падение узкого диапазона в конце.

Обращение в функции размыкания контакта (завершение интервью), как и в функции установления контакта, может не иметь мелодического маркера и продолжать мелодический рисунок предыдущей части, составляя одну синтагму с ней.

\section{Заключение}

Коммуникативная особенность реализации обращения в жанре интервью проявляется в его соседстве с другими этикетными речевыми актами (приветствия, благодарности, представления и т. д.), при этом в исследованных интервью обращение не отличается позиционной регламентированностью в коммуникативной структуре высказывания: оно может находиться в препозиции, интерпозиции или постпозиции к основной части высказывания.

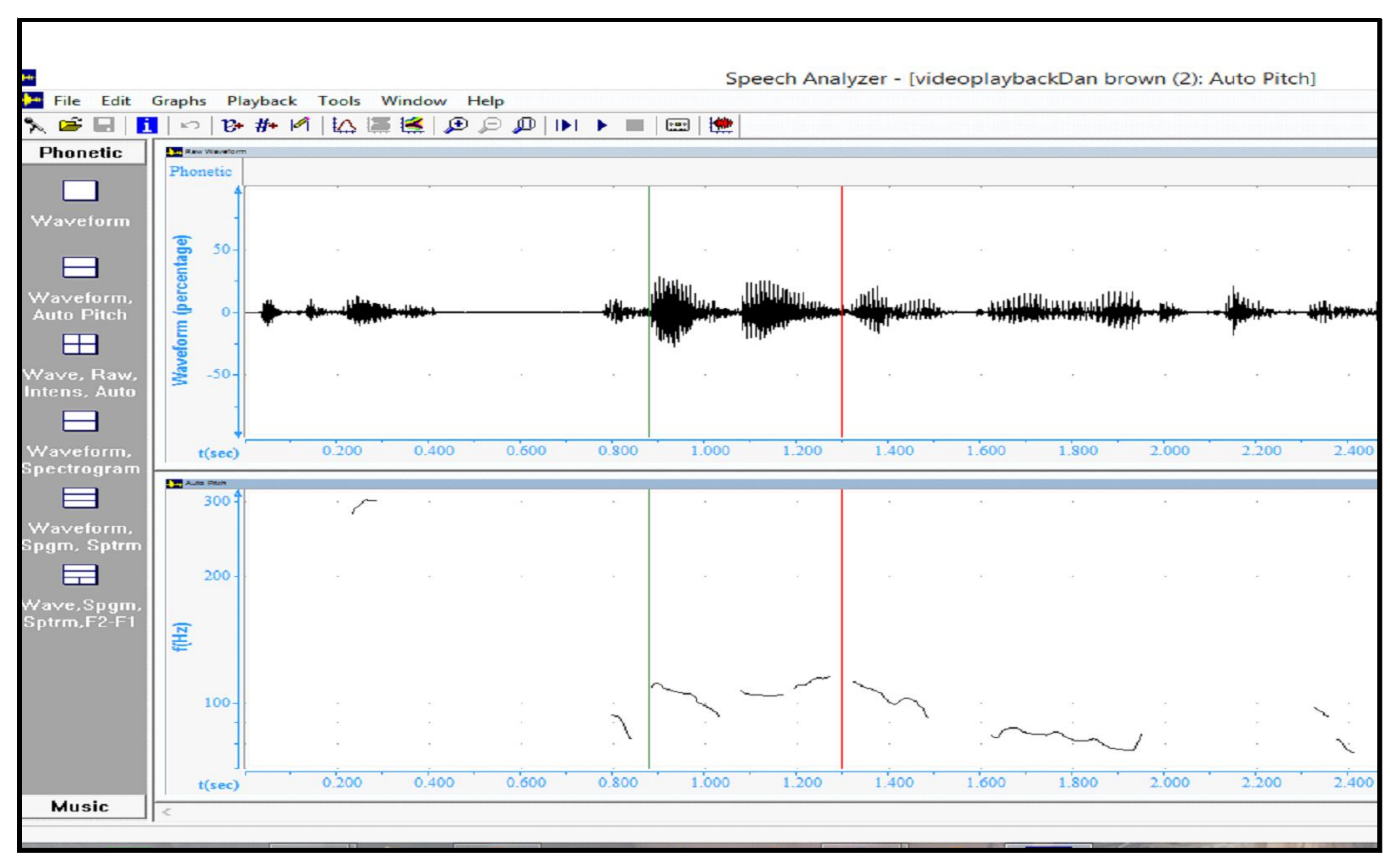

Рис. 6. Интонограмма предложения Dan Brown, we have to end it there 


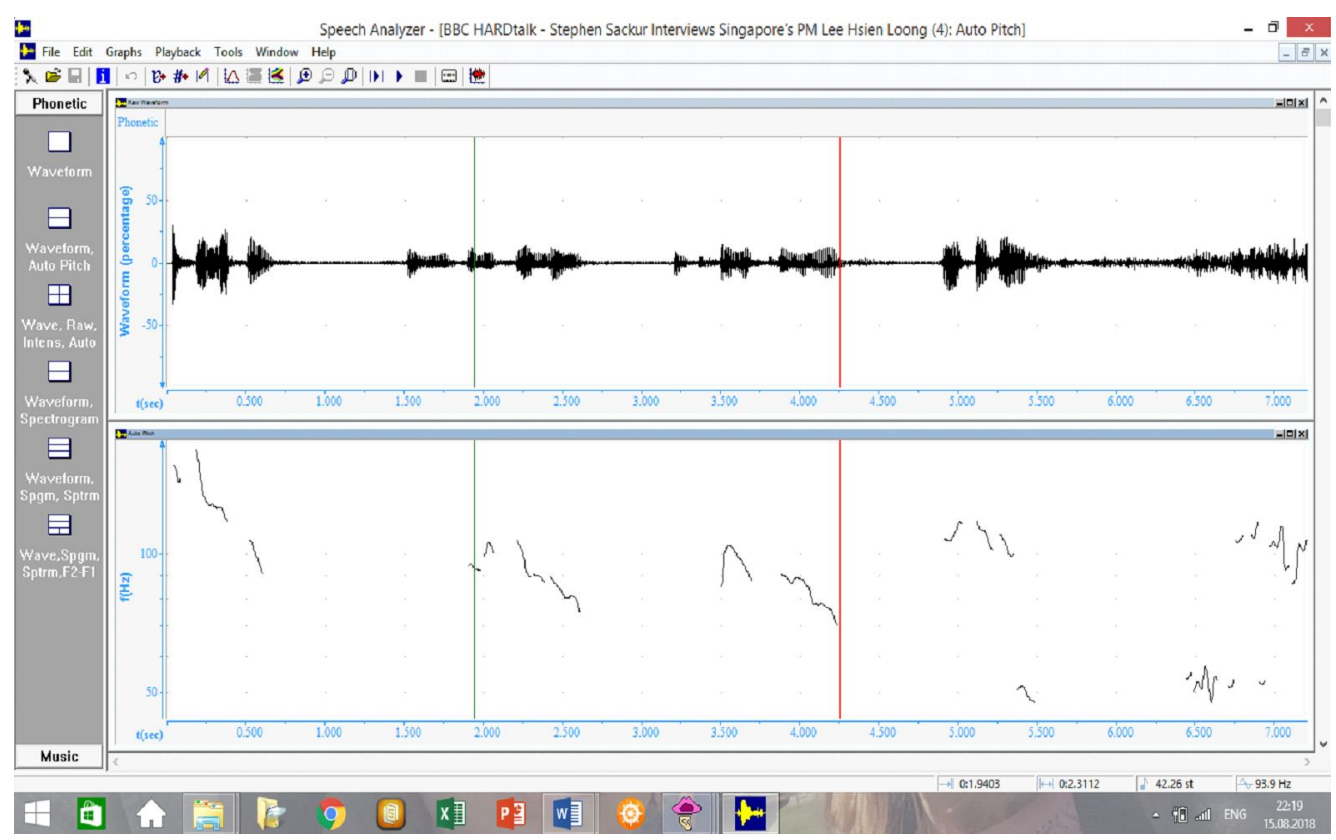

Рис. 7. Интонограмма предложения Prime Minister Lee Hsien Loong, thank you so much for being on HARD Talk

Важнейшая функция обращения в интервью - фатическая, ее реализация способствует установлению, поддержанию, восстановлению и размыканию контакта. Кроме того, обращение в интервью служит для привлечения внимания, включения в общение, переключения ролей между говорящими.

Проведенный анализ свидетельствует о том, что в начале интервью обращение может находиться в препозиции, постпозиции или в абсолютной позиции к другим речевым актам. Для обращения в препозиции свойственен ровный, низкий нисходящий или средний нисходящий тон, в постпозиции обращение, как правило, не образует отдельной синтагмы и продолжает мелодический паттерн предыдущего высказывания. В абсолютной позиции обращение может быть оформлено восходяще-нисходящим тоном.

В основной части интервью обращение полифункционально, что выражается в возможности реализации функции возобновления контакта, привлечения внимания слушающего к теме дискуссии, смены ролей, поддержания контакта, размыкания контакта, смены тональности. Для этой части интервью характерны препозиция и интерпозиция обращения. Мелодические паттерны обращения разнообразны, преобладают нисходящий (низкого и среднего уровней), нисходяще-восходящий, низкий восходящий тоны. Среди основных фак- торов, определяющих мелодический рисунок, - позициональные и функциональные характеристики исследуемых единиц.

Обращение является облигаторным элементом финальной части интервью и реализуется в препозиции к таким речевым актам, как прощание, благодарность, комплимент. В функции размыкания контакта обращение может быть оформлено низким нисходящим, средним нисходящим или нисходяще-восходящим тоном. Обращение может не иметь самостоятельного мелодического рисунка, а быть частью сложного мелодического контуpa. Особенность обращения в конце интервью составляет возможность использования мелодического паттерна, который повторяет мелодику последующего речевого акта.

\section{СПИСОК ЛИТЕРАТУРЫ}

Артемова Л. А., 2016. Функции именования автора и референта в медийных сообщениях различных жанров // Вестник Воронежского государственного университета. Серия: Лингвистика и межкультурная коммуникация. № 4. C. $35-40$.

Гольдин В. Е., 2009. Обращение: теоретические проблемы. М. : ЛИБРОКОМ. $136 \mathrm{c.}$

Карасик В. И., 1992. Язык социального статуса. М. : Институт языкознания РАН ; Волгогр. гос. пед. ин-т. 330 с. 
Н.Ю. Сороколетова. Вариативность мелодических паттернов обращения в англоязычном интервью

Кожухова Л. В., 2007. Речевой акт обращения // Вестник Ставропольского государственного университета. № 48. С. 80-85.

Формановская Н. И., 1989. Речевой этикет и культура общения. М. : Высшая школа. 159 с.

Янко Т. Е., 2010. Обращения в структуре дискурca // Логический анализ языка. Моно-, диа-, полилог в разных культурах / отв. ред. Н. Д. Арутюнова. М. : Индрик. С. 456-468.

Янковская И. В., 2012. Роль маркеров в организации структуры интервью (когнитивно-дискурсивный подход) // Вестник Московского государственного лингвистического университета. Гуманитарные науки. № 639. С. 311-320.

\section{REFERENCES}

Artemova L.A., 2016. Functions of author and referent's nominations in mass media texts of various genres. Vestnik Voronezhskogo gosudarstvennogo universiteta. Seriya: Lingvistika i mezhkulturnaya kommunikatsiya [Proceedings of Voronezh State University. Series:
Linguistics and intercultural communication], no. 4, pp. 35-40.

Goldin V.E., 2009. Form of address: theoretical issues. Moscow, LIBROKOM Publ. $136 \mathrm{p}$.

Karasik V.I., 1992. Language of Social Status. Moscow, In-t yazykoznaniya RAN; Volgogr. gos. ped. in-t Publ., 1992.330p.

Kozhukhova L.V., 2007. Vocative speech act. Vestnik Stavropolskogo gosudarstvennogo universiteta, no. 48 , pp. $80-85$.

Formanovskaya N.I., 1989. Speech Etiquette and Culture of Communication. Moscow, Vysshaya shkola Publ. 159 p.

Yanko T.E., 2010. Vocativity in a discourse structure. Logical analysis of the language: mono-, dia-, polylogue in different languages and cultures. Moscow, Indrik Publ., pp. 456-468.

Yankovskaya I.V., 2012. Role of discourse markers in TV interview structure (cognitive and discourse approach). Vestnik Moskovskogo gosudarstvennogo lingvisticheskogo universiteta. Gumanitarnye nauki [Vestnik of Moscow State Linguistic University. Humanities], no. 639, pp. 311-320.

\section{Information about the Author}

Natalya Yu. Sorokoletova, Candidate of Sciences (Philology), Associate Professor, Department of English Philology, Volgograd State University, Prosp. Universitetsky, 100, 400062 Volgograd, Russia, sorokoletovanat@volsu.ru, english_philology@mail.ru,https://orcid.org/0000-0002-6680-0911

\section{Информация об авторе}

Наталья Юрьевна Сороколетова, кандидат филологических наук, доцент, доцент кафедры английской филологии, Волгоградский государственный университет, просп. Университетский, 100, 400062 г. Волгоград, Россия, sorokoletovanat@volsu.ru, english_philology@mail.ru, https:// orcid.org/0000-0002-6680-0911 